\title{
Titanium Oxide Modification With Oxides of Mixed Cobalt Valence for Photocatalysis
}

\author{
Roberto Alanís-Oaxaca and Jaime Jiménez-Becerril*
}

Instituto Nacional de Investigaciones Nucleares, Departamento de Química. Carretera México Toluca S/N, La Marquesa, Ocoyoacac 52750, México, D.F. jaime.jimenez@inin.gob.mx

Received February 5, 2010; Accepted May 28, 2010

\begin{abstract}
In the present work, heterogenous photocatalysis, a technique often used for organic compound degradation toxic in water, was used. The photocatalyst most often used in this technique is $\mathrm{TiO}_{2}$, which, due to its physical and chemical properties, can degrade a great number of organic compounds. In addition, in recent years it has been verified that the doping of semiconductors with metals or metallic oxides increases the photocatalytic activity of these semiconductors, which is why it was proposed for doping by the impregnating method using commercial $\mathrm{TiO}_{2}$ synthesized by the Degussa company $\left(\mathrm{TiO}_{2}\right.$ Degussa P25) with an oxide of mixed cobalt valence $\left(\mathrm{Co}_{3} \mathrm{O}_{4}\right)$ synthesized using the sol-gel method. The synthesized photocatalyst $\mathrm{TiO}_{2} / \mathrm{Co}_{3} \mathrm{O}_{4}$ was characterized by the techniques of X-ray diffraction (RXD), scanning electronic microscopy (SEM), Raman spectroscopy (RS), and, finally, photocatalytic tests by means of the degradation of methylene blue.

Keywords: Photocatalysis, Methylene Blue.
\end{abstract}

\section{Introduction}

Advanced oxidation technologies are defined as processes that involve the generation and use of reactive transitory species, mainly radical hydroxyl $\left(\mathrm{HO}^{\bullet}\right)$, which can be generated by photochemical means (including the solar light) or by other forms of energy and has discharge effectiveness for the oxidation of organic matter [1].

One advantage of these technologies is that transforming chemically polluting agents, generally, ensures the complete mineralization (destruction) of the organic matter, useful in handling refractory polluting agents that resist other methods, reducing polluting agents to very low concentration (for example, ppm), forming no by-products, in forming in low concentration, among others advantages [2].

The semiconductors of interest in photocatalysis are solid, generally oxides, where the atoms constitute an infinite threedimensional network. Diverse materials with suitable semiconductor properties, chemically stable metallic oxides with high superficial area, uniform pore size, etc., act like catalysts and carry out photo reactions. The majority of these materials can be excited with light of not very high energy, absorbing part of the radiation of the solar spectrum that affects the terrestrial surface, which increases the interest for a possible advantage of solar light.

$\mathrm{TiO}_{2}$ Degussa P25 is the commercial catalyst that was used in the present work, which is why it is important to know the characteristics of this material. $\mathrm{TiO}_{2}$ Degussa P25
Resumen. En el presente trabajo se utilizó la fotocatálisis heterogénea, que es una de las técnicas más utilizadas en la degradación de compuestos orgánicos tóxicos presentes en agua. El fotocatalizador más usado por esta técnica es el $\mathrm{TiO}_{2}$ el cual, debido a sus propiedades físicas y químicas puede degradar un gran número de compuestos orgánicos. Aunado a lo anterior, en los últimos años se ha comprobado que el dopaje de semiconductores con metales u óxidos metálicos aumenta la actividad fotocatalítica de estos semiconductores, por lo que se propuso dopar por el método de impregnación al $\mathrm{TiO}_{2}$ comercial sintetizado por la empresa Degussa $\left(\mathrm{TiO}_{2}\right.$ Degussa $\mathrm{P} 25)$ con un óxido de valencia mixta de cobalto $\left(\mathrm{Co}_{3} \mathrm{O}_{4}\right)$, el cual fue sintetizado por el método sol - gel. El fotocatalizador sintetizado $\mathrm{TiO}_{2} / \mathrm{Co}_{3} \mathrm{O}_{4}$, se caracterizó por las técnicas de Difracción de Rayos X (DRX) de polvos, Microscopía Electrónica de Barrido (MEB) y Espectroscopía Raman (ER), por último, se le realizaron pruebas fotocatalíticas mediante la degradación de azul de metileno.

Palabras clave: Fotocatálisis, azul de metileno.

consists of an $80: 20 \%$ mixture of the anatase and rutile structures, respectively. It has high photoreactivity, which has been suggested must, indeed, be a result of the presence of both structures (anatase and rutile) and promote the separation of the electron-hollow pair, inhibiting its recombination [3]. It is a nonporous material with a density of $3.7 \mathrm{~g} / \mathrm{cm}^{3}$ and specific surface BET area of $55 \mathrm{~m}^{2} \mathrm{~g}^{-1}$ [4]. On the other hand, methylene blue is a crystalline or polycrystalline dust of a dark green color, with bronzed brightness, no odor, stability in air; their alcohol or water solutions are of an intense blue color. It is very soluble in water and moderately soluble in chloroform and alcohol, its chemical formula is $\mathrm{C}_{16} \mathrm{H}_{18} \mathrm{~N}_{3} \mathrm{ClS}$, and its molecular weight $319.85 \mathrm{~g} / \mathrm{mol}$, with a maximum absorption in $\lambda=665 \mathrm{~nm}$ [5].

Methylene blue is a good substrate to be used in heterogenous photocatalysis, since as showed [6], using the photocatalysis based on $\mathrm{TiO}_{2} / \mathrm{UV}$ on a series of compounds with a complete carbon mineralization to $\mathrm{CO}_{2}$, methylene blue was degraded successfully; they also calculated the initial speeds of disappearance of coloring in $\mu \mathrm{mol} / \mathrm{L}$.min. Also, they found that the $\mathrm{pH}$ has a small influence on the kinetic of disappearance of methylene blue, in addition to showing its stoichiometric equation of total oxidation.

A large number of studies have employed $\mathrm{TiO}_{2}$ due to its great importance in industrial applications. Kamat [7] reported that different ionic metals from transition deposited on the surface of semiconductors could improve the separation of photogenerated electron-hollow pairs and increase the photocatalytic activity of the $\mathrm{TiO}_{2}$. 
Subramanian et al. [8] proved the effect of doping with cobalt (II) in the structure and optical properties of $\mathrm{TiO}_{2}$ films prepared by the sol-gel process, obtaining nanocrystalline films with a great size at an interval of 10-25 nm. Pore density depends on the cobalt amount; the best films, almost free of pores, can be prepared with $15 \%$ cobalt or more. It was found that the refractive index of the films increased and the band gap simultaneously decreased, along with the increase of the concentration cobalt, which is attributed to the insertion of impurities in the energy band of the $\mathrm{TiO}_{2}$. The reduction in the band gap (from $476 \mathrm{~nm}, 3.19 \mathrm{eV}$ with $0 \%$ cobalt in weight to $370 \mathrm{~nm}$ and $2.77 \mathrm{eV}$ with $15 \%$ in weight of $\mathrm{Co}$ ) was favorable for increasing the photocatalytic activity of the $\mathrm{TiO}_{2}$ in the visible region.

Cobalt oxide $\left(\mathrm{Co}_{3} \mathrm{O}_{4}\right)$ is formed when a compound of cobalt, such as a carbonate or hydrate were warmed up in the presence of air to temperatures over $265^{\circ} \mathrm{C}$ and not exceeding $800^{\circ} \mathrm{C}$. This is a stable black oxide that is reduced easily to its metallic form using carbon, carbon monoxide, or hydrogen [9]. Some of the potential applications of $\mathrm{Co}_{3} \mathrm{O}_{4}$ are in electronic deposits, enamels, heterogenous gas sensors, catalysts, precursor in anodic materials in reloadable ion-Li batteries, semiconductors, absorbers of nuclear power, and so on.

$\mathrm{Co}_{3} \mathrm{O}_{4}$ can be synthesized using diverse procedures; one of them is the sol-gel method, which was used in this project. Luo et al. [10] synthesized nanostructures of $\mathrm{Co}_{3} \mathrm{O}_{4}$ using a complex method using $\mathrm{Co}\left(\mathrm{NO}_{3}\right)_{2} \bullet 6 \mathrm{H}_{2} \mathrm{O}, \mathrm{NH}_{3} \bullet \mathrm{OH}$ and $\mathrm{H}_{2} \mathrm{O}_{2}$, obtaining particles with a uniform diameter of $20 \mathrm{~nm}$ at 550 ${ }^{\circ} \mathrm{C}$. Once the catalyst was synthesized, it was used in the degradation Black Reagent (B-GFF), Blue Turkish Reagent (B-RN), and Blue Turkish Reagent (K-NR). Nevertheless, the $\mathrm{Co}_{3} \mathrm{O}_{4}$ burnout to a temperature of $300{ }^{\circ} \mathrm{C}$ shows greater photocatalytic activity with respect to the burnout to $550{ }^{\circ} \mathrm{C}$ when degrading compounds more than $90 \%[10]$.

It has been reported [11] that the heterounions between semiconductors of type $p$ and type $n$ exhibit an increase in photocatalytic activity. As mentioned previously, $\mathrm{TiO}_{2}$ is a semiconductor of type $n$ and $\mathrm{Co}_{3} \mathrm{O}_{4}$ is a semiconductor of type $\mathrm{p}$, which is why a heterounion could be carried out to create a type $p-n$. The structure of these bondings with semiconductors of type $p$ - $n$, like the photocatalyst $\mathrm{Co}_{3} \mathrm{O}_{4} / \mathrm{BiVO}_{4}$, exhibits an increase in the photocatalytic activity in the degradation of phenol under the irradiation of visible light, which was attributed to the structure of heterounions with semiconductors of type $p-n$ and to the diminution in the recombination of electron-hollow pairs. On the other hand, Xiao et al. [12] synthesized by means of a hydrothermal process the photocatalyst $\mathrm{Co}_{3} \mathrm{O}_{4} / \mathrm{Bi}_{2} \mathrm{WO}_{6}$ such that these semiconductors formed a composite with heterounions of type $p-n$ and verified their photoactivity with the degradation of methylene blue under irradiation of visible light. In this case, they demonstrated that when doping to the $\mathrm{Bi}_{2} \mathrm{WO}_{6}$ in a $0.2 \%$ weight with $\mathrm{Co}_{3} \mathrm{O}_{4}$, the composite increased its photocatalytic activity and resulted in an effective separation of the electron-hollow pairs.

\section{Results and discussion}

The techniques of X-ray diffraction for all of the catalysts synthesized in different percentages from $\mathrm{Co}_{3} \mathrm{O}_{4}$, as well as the $\mathrm{TiO}_{2}$ Degussa P25, are shown in Figure 1.

The compounds present in the samples are the anatase and rutile phases of titanium oxide, and the peaks fit well with those assigned in JCDPS cards. When comparing the difractograms of the synthesized catalysts that were modified with $\mathrm{Co}_{3} \mathrm{O}_{4}$, it was observed that the $\mathrm{TiO}_{2}$ samples showed no changes in crystallinity, direction of crystals, or changes of phase. When comparing the difractograms of $\mathrm{TiO}_{2}$ that were modified with $\mathrm{Co}_{3} \mathrm{O}_{4}$, it was not possible to observe peaks of the $\mathrm{Co}_{3} \mathrm{O}_{4}$ due to the sensitivity of the used technique. With the equipment used, the compounds present that are in a greater percentage than $5 \%$ in proportion to the total amount of the sample are shown, and in the synthesized catalysts, the one with the greater proportion than the modified samples was that of $0.47 \%$; that is why, with this technique, it was not possible to identify the $\mathrm{Co}_{3} \mathrm{O}_{4}$ in the modified catalysts.

Alternatively to the $\mathrm{X}$-ray diffraction technique to identify to the $\mathrm{Co}_{3} \mathrm{O}_{4}$ in the samples of the synthesized catalyst $\left(\mathrm{TiO}_{2} /\right.$ $\mathrm{Co}_{3} \mathrm{O}_{4}$ ), Raman spectroscopy was used; the results obtained are shown in Figure 2. In the obtained spectra for the samples of $\mathrm{TiO}_{2}$, unfortunately, it was not possible to observe the $\mathrm{Co}_{3} \mathrm{O}_{4}$ in the spectra since all peaks that corresponded only to the $\mathrm{TiO}_{2}$ in wave numbers of $90,400,510$, and $630 \mathrm{~cm}^{-1}$.

The scanning electron microscopy results are shown in Figure 3. When comparing Figures $3 a, 3 b$, and $3 c$, it was possible to observe that, in fact, there was no significant difference between the samples of the catalysts of $\mathrm{TiO}_{2}$ that were modified with $\mathrm{Co}_{3} \mathrm{O}_{4}$; this is because the mixed oxide was in a too-low amount in the samples, which was observed as corresponding only to the $\mathrm{TiO}_{2}$ since these were very similar to the sample of Figure 3d; the morphology of the samples was clusters of amorphous grains.

The elementary semiquantitative analysis by EDS provided information about the existing elements in a sample, in

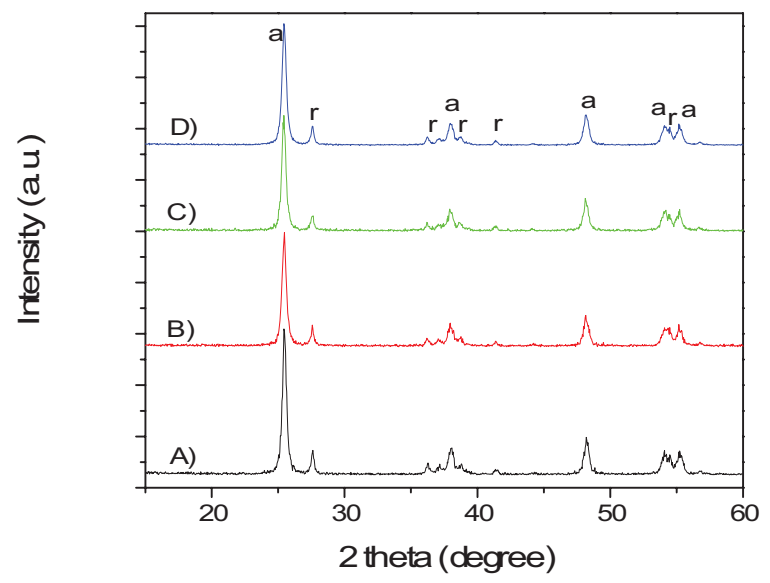

Fig. 1. X-ray difractograms of powder samples, A) $\mathrm{TiO}_{2} / \mathrm{Co}_{3} \mathrm{O}_{4}$ $0.07 \%$, B) $\mathrm{TiO}_{2} / \mathrm{Co}_{3} \mathrm{O}_{4} 0.26 \%$, C) $\mathrm{TiO}_{2} / \mathrm{Co}_{3} \mathrm{O}_{4} 0.47 \%$, and D) $\mathrm{TiO}_{2}$ Degussa P25, a $=$ anatase, $\mathrm{r}=$ rutile. 


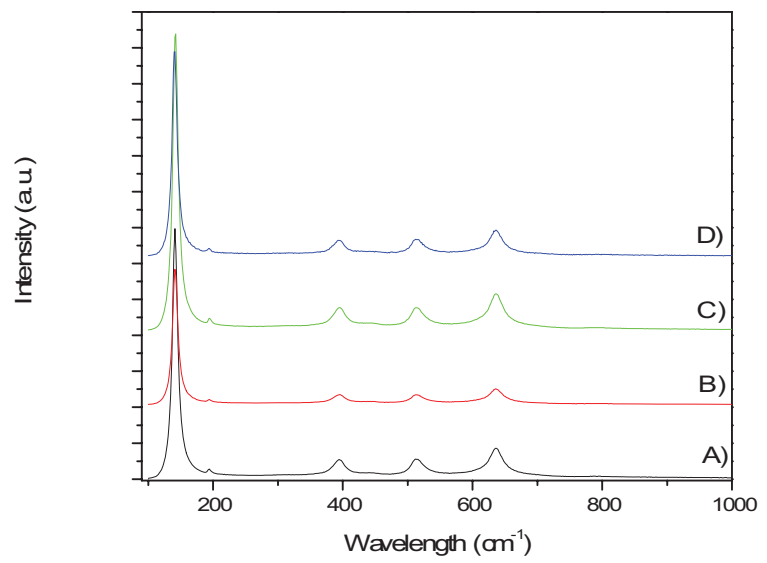

Fig. 2. Raman spectra of $\mathrm{TiO}_{2}$ undoped and doped with $\mathrm{Co}_{3} \mathrm{O}_{4} \mathrm{~A}$ ) $0.47 \%$, B) $0.26 \%$, C) $0.07 \%$, and D) $\mathrm{TiO}_{2}$ Degussa P25.


Fig. 3. SEM of $\mathrm{TiO}_{2}$ doped and undoped with $\mathrm{Co}_{3} \mathrm{O}_{4}$. A) 0.07, B) 0.26, C) $0.47 \%$, and D) Degussa P25.

addition to showing their atomic percentage. In the Table 1 sample, mixed cobalt oxide was present in very small amounts, that is to say, as planned, which is very important, because this is a unique method in which the presence of this compound in the synthesized catalysts is demonstrated since it could not be observed by X-ray diffraction or by Raman spectroscopy. It should be mentioned that when comparing the atomic percentage of cobalt in the samples, it was observed that there was a greater amount of cobalt presence in the catalyst that was modified with a smaller amount, which can be attributed to the

Table 1. Elementary semiquantitative analysis by EDS.

\begin{tabular}{lcccc}
\hline \multicolumn{1}{c}{ Sample } & \multicolumn{4}{c}{ Atomic percentage } \\
\cline { 2 - 5 } & $\mathrm{O}$ & $\mathrm{Ti}$ & $\mathrm{Co}$ & $\mathrm{C}$ \\
\hline $\mathrm{TiO}_{2} / \mathrm{Co}_{3} \mathrm{O}_{4}-0.07 \%$ & 58.50 & 41.41 & 0.09 & -- \\
$\mathrm{TiO}_{2} / \mathrm{Co}_{3} \mathrm{O}_{4}-0.26 \%$ & 66.73 & 33.20 & 0.06 & -- \\
$\mathrm{TiO}_{2} / \mathrm{Co}_{3} \mathrm{O}_{4}-0.47 \%$ & 62.82 & 37.06 & 0.12 & -- \\
$\mathrm{TiO}_{2}$ & 63.6 & 36.4 & -- & -- \\
$\mathrm{Co}_{3} \mathrm{O}_{4}$ & 27.9 & -- & 18.3 & 53.8 \\
\hline
\end{tabular}

fact that the distribution of mixed cobalt oxide on the surface of titanium could not be uniform.

\section{Photoactivity}

Degradation of methylene blue. The kinetic of reaction of degradation of methylene blue was obtained by varying the concentration of dyestuff. In samples of $100 \mathrm{ml}$ of methylene blue of different concentrations $(2,5,10,15<$ and $20 \mathrm{ppm})$ photodegradation was realized with titanium oxide Degussa P25, and the data were standardized by means of the $\mathrm{C} /$ Co relation. There was a greater percentage of degradation of methylene blue when the concentration was smaller since it presented a good speed of degradation.

According to the data regarding the degradation of methylene blue shown in Figure 4, the kinetic of the photodegradation of the methylene blue from the model that Langmuir Hinshelwood was calculated, so it is assumed that the kinetic of the reaction in the interphase is of first order. The velocity of the process $(v)$ is written as follows:

$$
V=-d C / d t=k K C /(1+K C)
$$

where its inverse is:

$$
1 / V=1 / k+(1 / k \cdot K) \cdot 1 / C
$$

Where $k$ the $K$ and velocity constant of reaction the constant of the adsorption process. The results appear in Table 2.

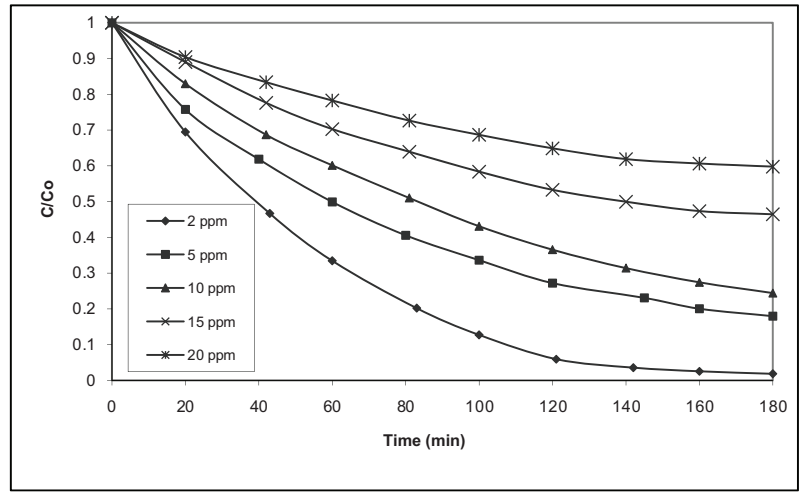

Fig. 4. Kinetics of degradation of methylene blue.

Table 2. Velocity and concentration values calculated from kinetic data.

\begin{tabular}{cccc}
\hline $\begin{array}{c}\mathrm{C}_{\mathrm{o}} \\
(\mathrm{mg} / \mathrm{L})\end{array}$ & $\begin{array}{c}\mathrm{V}_{\mathrm{o}} \\
(\mathrm{mg} / \mathrm{L} \cdot \mathrm{min})\end{array}$ & $\begin{array}{c}1 / \mathrm{C}_{\mathrm{o}} \\
(\mathrm{L} / \mathrm{mg})\end{array}$ & $\begin{array}{c}1 / \mathrm{V}_{\mathrm{o}} \\
(\mathrm{L} \cdot \mathrm{min} / \mathrm{mg})\end{array}$ \\
\hline 1.5 & 0.0013 & 0.65 & 751.7 \\
4.8 & 0.0035 & 0.20 & 281.5 \\
9.0 & 0.0047 & 0.11 & 211.4 \\
13.7 & 0.0043 & 0.07 & 229.5 \\
16.3 & 0.0047 & 0.06 & 208.9 \\
\hline
\end{tabular}


Later, these data were evaluated with the adjustment to the Langmuir-Hinshelwood equation, L-H; see Figure 5.

With the equation obtained from Figure 5, the kinetic constant and adsorption were calculated, corresponding to $\mathrm{k}=$ $7.707 \times 10^{-3} \mathrm{mg} / \mathrm{L} . \mathrm{min}$ and $\mathrm{K}=0.1383 \mathrm{~L} / \mathrm{mg}$, of which it can be said that in the conditions of this experiment, the adsorption of methylene blue on the surface of the catalyst was fast and, therefore, the obstacle stage is the chemical reaction of degradation.

\section{Degradation of methylene blue with $\mathrm{TiO}_{2} / \mathrm{Co}_{3} \mathrm{O}_{4}$}

In Figure 6, it is possible to observe that the velocity of degradation was greater when the catalyst containing $0.07 \%$ of $\mathrm{Co}_{3} \mathrm{O}_{4}$ was used, followed by the one containing $0.26 \%$ of $\mathrm{Co}_{3} \mathrm{O}_{4}$ and, finally, the one containing $0.47 \%$ of $\mathrm{Co}_{3} \mathrm{O}_{4}$. This can indicate that the greater cobalt oxide concentration produces a screen effect that inhibits the charge separation.

Figure 7 presents the graphs obtained showing the degradation of $\mathrm{TiO}_{2}$ and $\mathrm{Co}_{3} \mathrm{O}_{4}$ with and without UV light, in addition to the graph of an experiment using the catalyst of synthesized $\mathrm{TiO}_{2} / \mathrm{Co}_{3} \mathrm{O}_{4}$ that presented greater photoactivity. In this figure, it is possible to observe that the photocatalysts presenting greater degradation of methylene blue were $\mathrm{TiO}_{2}$



Fig. 5. L-H plot adjustment from the kinetic data of methylene blue photodegradation.

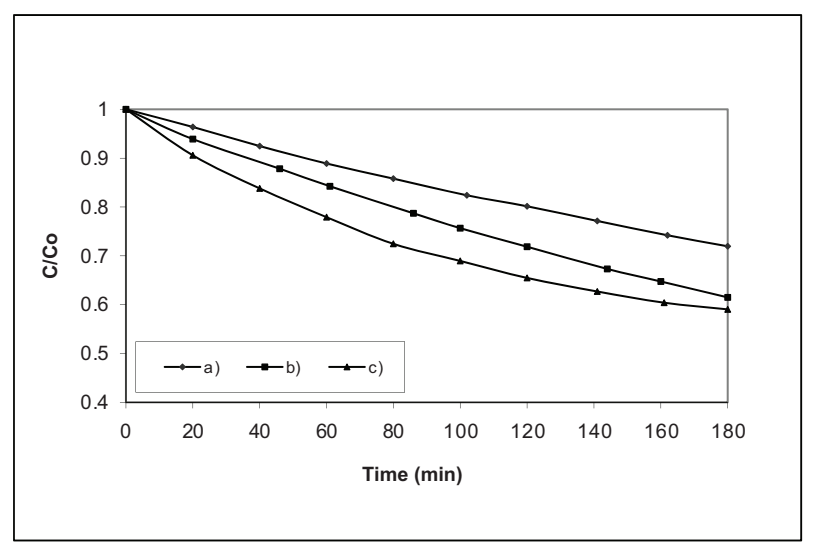

Fig. 6. Photodegradation plot of methylene blue using different catalysts. A) $0.47 \%$, B) $0.27 \%$, C) $0.07 \% ; \mathrm{TiO}_{2} / \mathrm{Co}_{3} \mathrm{O}_{4}\left(\mathrm{C}_{\mathrm{o}}=10 \mathrm{ppm}\right.$, $1 \mathrm{~g}$ catalyst/L solution).

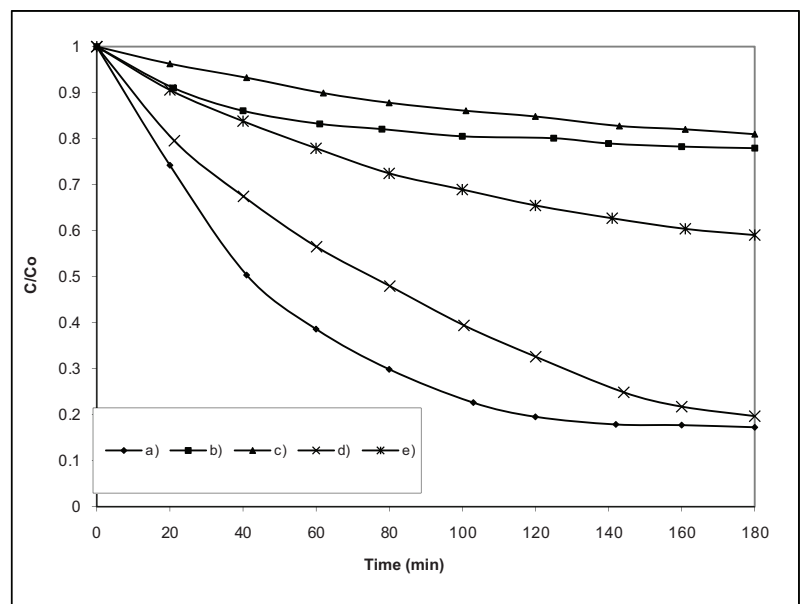

Fig. 7. Comparative graphic of the photodegradation of methylene blue using different catalysts. A) $\mathrm{Co}_{3} \mathrm{O}_{4}$ plus UV light, B) $\mathrm{Co}_{3} \mathrm{O}_{4}$ without light, C) $\mathrm{TiO}_{2}$ without light, D) $\mathrm{TiO}_{2}$ with light, and E) $\mathrm{TiO}_{2}$ $/ \mathrm{Co}_{3} \mathrm{O}_{4}-0.07 \%$ with light.

and $\mathrm{Co}_{3} \mathrm{O}_{4}$, both with UV light (Figures $7 \mathrm{a}$ and $7 \mathrm{~d}$ ); the curve that presents $\mathrm{Co}_{3} \mathrm{O}_{4}$ shows a slightly greater degradation than one for $\mathrm{TiO}_{2}$, in addition to being better defined.

According to reports in the literature for other modified photocatalysts, such as $\mathrm{Co}_{3} \mathrm{O}_{4} / \mathrm{Bi}_{2} \mathrm{WO}_{6}$ (Xiao, 2008), the synthesized catalyst $\left(\mathrm{TiO}_{2} / \mathrm{Co}_{3} \mathrm{O}_{4}\right)$ would have to present greater photoactivity since the presence of $\mathrm{Co}_{3} \mathrm{O}_{4}$ in very small amounts (as impurities) in the $\mathrm{TiO}_{2}$ would diminish the generation of electron-hollow pairs, increasing the photoactivity of the catalyst. There are diverse causes that can explain why an increase in the photoactivity of the synthesized catalyst $\mathrm{TiO}_{2} / \mathrm{Co}_{3} \mathrm{O}_{4}$ did not occur as expected compared to the use of $\mathrm{TiO}_{2}$ and $\mathrm{Co}_{3} \mathrm{O}_{4}$ separately; one of them is that in the modified catalyst, the $\mathrm{Co}_{3} \mathrm{O}_{4}$ is only on the surface of the $\mathrm{TiO}_{2}$ and they do not form any important chemical interactions among them, which is why the generation of electron-hollow pairs is inefficient.

An option to determine that an important chemical interaction between the $\mathrm{TiO}_{2}$ and the $\mathrm{Co}_{3} \mathrm{O}_{4}$ occurred is to synthesize both oxides using sol-gel instead of impregnating the $\mathrm{TiO}_{2}$ Degussa P25 and the calcination of both compounds; it is probable that the chemical interactions are weak.

\section{Conclusion}

From catalysts of synthesized $\mathrm{TiO}_{2} / \mathrm{Co}_{3} \mathrm{O}_{4}$, the order of photoactivity was $0.07>0.26>047 \%$ of cobalt ratio, indicating that if the amount of $\mathrm{Co}_{3} \mathrm{O}_{4}$ in the $\mathrm{TiO}_{2}$ is lower, photoactivity constitutes the major factor in the degradation of methylene blue. When comparing the photoactivity of the synthesized $\mathrm{TiO}_{2} / \mathrm{Co}_{3} \mathrm{O}_{4}$ with the precursors $\mathrm{TiO}_{2}$ and $\mathrm{Co}_{3} \mathrm{O}_{4}$, it was observed that photoactivity was lower in the prepared samples than in the precursors because in adding $\mathrm{Co}_{3} \mathrm{O}_{4}$ to the $\mathrm{TiO}_{2}$ by means of the method of modification used in the present work, the chemical interaction obtained between the $\mathrm{TiO}_{2}$ and $\mathrm{Co}_{3} \mathrm{O}_{4}$ is weak. 


\section{Experimental}

Synthesis of the photocatalyst $\mathrm{TiO}_{2} / \mathrm{Co}_{3} \mathrm{O}_{4}$

a) Preparation of cobalt malonate using the sol-gel method. Cobalt malonate was prepared according to the technique used by Morales [13], in which $\mathrm{CoCO}_{3}$ was prepared by adding 50 $\mathrm{mL}$ of a cobalt nitrate $1 \mathrm{M}$ aqueous solution to a sodium carbonate, which was shaken for $15 \mathrm{~min}$. The obtained precipitate was filtered and washed with distilled water until the washing water reached a neutral $\mathrm{pH}$. After $\mathrm{CoCO}_{3}$ preparation, it was dissolved in an aqueous solution of $1 \mathrm{M}$ maleic acid with glycerol added, making them react at $70^{\circ} \mathrm{C}$ with constant agitation for $1 \mathrm{~h}$. After this time, it was cooled to $30^{\circ} \mathrm{C}$ for $48 \mathrm{~h}$. until it formed a gel. The $\mathrm{Co}_{3} \mathrm{O}_{4}$ was obtained when the obtained gel was calcinated at $300^{\circ} \mathrm{C}$ for $3 \mathrm{~h}$.

b) Modification of the $\mathrm{TiO}_{2}$ with $\mathrm{Co}_{3} \mathrm{O}_{4}$. The gel of cobalt (II) malonate was dried at $100^{\circ} \mathrm{C}$ for $3 \mathrm{~h}$; the dry gel can be handled like a dust, the dust of cobalt malonate was mixed with $0.1 \mathrm{~g}$ of $\mathrm{TiO}_{2}$ Degussa P25 in different percentages of cobalt weight, $0.1,0.5$, and 1.0 , corresponding to $0.07,0.26$, and $0.47 \%$ of the $\mathrm{TiO}_{2} \mathrm{Co}_{3} \mathrm{O}_{4}$ relation, by means of incipient impregnating.

c) Characterization of the photocatalysts.

$\mathrm{X}$-ray diffraction. This technique was applied for the characterization of the synthesized materials $\left(\mathrm{TiO}_{2} / \mathrm{Co}_{3} \mathrm{O}_{4}\right), \mathrm{Co}_{3} \mathrm{O}_{4}$ and $\mathrm{TiO}_{2}$ Degussa P25, with a SIEMENS D-5000 difractometer coupled to an X-ray tube $\mathrm{Cu}$ anode.

Raman spectroscopy. Microraman equipment in the backscattering configuration (LabRam HR 800) was used.

Scanning electronic microscopy. A scanning electron microscope, JEOL JMS 5900LV Philips XL-30, was used, equipped with microsounding OXFORD for elementary semiquantitative chemical analysis. The scanning electron micrograph and analysis by X-ray dispersion (energy dispersive $\mathrm{X}$-ray analysis) were use to conduct the semiquantitative elementary chemical analysis. Characteristic X-rays produced by the Auger effect allow for the analysis of the chemical components of the sample by means of a spectrometer of energy of scattered x-rays connected to the scanning electron microscope (Golstein, 1994). d) Photoactivity of prepared catalysts in methylene blue degradation.

All of the experiments were realized in a totally dark room with an air flow of $20 \mathrm{~cm}^{3} / \mathrm{min}$ and constant agitation for $3 \mathrm{~h}$; at the beginning, a $5 \mathrm{~mL}$ sample of aliquot was taken with a syringe, and once the experiment began, samples were taken every $20 \mathrm{~min}$, each one filtered with a Millipore membrane of $0.45 \mu \mathrm{m}$ pore diameters. Later, the absorbance in UV-Vis of the samples was obtained in the experiment using a spectrophotometer SHIMADZU to a wavelength of $\lambda=665 \mathrm{~nm}$, the maximum length that methylene blue can absorb (Shimizu et al., 2006).

\section{References}

1. Glaze, W. H.; Kang, J. W.; Chapin, D. H. Ozone Sci. Eng. 1987, 9, 335-352.

2. Domènech, X.; Jardim, W. F.; Litter M. I., in: Eliminación de Contaminantes por Fotocatálisis Heterogénea, Blesa, M. A., Ed., Red CYTED VIII-G, 2001, 22-25.

3. Bickley, R. I.; González-Carreno, T.; Lees, J. S.; Palmisano, L.; Tilley, R. J. D. J. Solid State Chem. 1991, 92, 178-190.

4. Ettlinger, M. Technical Bulletin Pigments, Degussa AG, Inorganic Chemical Products Division: Düsseldorf, 1993, 80, 1-26.

5. Shimizu, N.; Ogino, C.; Dadjour, M. F.; Murata T. Ultrason. Sonochem. 2007, 14, 184-190.

6. Lachheb, H.; Puzenat, E.; Houas, A.; Ksibi, M.; Elaloui, E.; Guillard, C.; Herrmann, J. M. Appl. Catal. B: Environ. 2002, 39, 75-90.

7. Kamat, P. V.; Huehn, R.; Nicolaescu, R. J. Phys. Chem. B 2002, 106, 788-794.

8. Subramanian, M.; Vijayalakshmi, S.; Venkataraj, S.; Jayavel, R. Thin Solid Films 2008, 516, 3776-3782.

9. Young, R. S. Cobalt. Its chemistry, metallurgy and uses. Ed. Reinhold Publishing Corporation, New York, 1960.

10. Luo, X.; Han, J.; Chu, W.; Wang, X.; Cheng, Q. Mater. Sci. Eng. B 2007, 137, 268-271.

11. Long, M.; Cai, W.; Cai, J.; Zhou, B.; Chai, X.; Wu, Y. J. Phys. Chem. B, 2006, 110, 20211-20216.

12. Xiao, Q.; Zhang, J.; Xiao, C.; Tan, X. Catal. Commun. 2008, 9, 1247-1253.

13. Morales Gil, P. BSc. Thesis: Sintesis y caracterización de óxidos cobalto - níquel para la reacción de formación de oxígeno. Facultad de Química, UAEM, Mexico, 2001. 